\title{
Algunos problemas de estética y hermenéutica
}

\author{
AMADOR VEGA \\ Facultat d'Humanitats \\ Universitat Pompeu Fabra (Barcelona) \\ amador.vega@upf.edu
}

Resumen: Respuestas a Isabel Cabrera y Zenia Yébenes Escardó relativas a la posibilidad de una estética apofática y sus relaciones con la experiencia de lo sagrado en el arte. Se vuelve a discutir la pertinencia de la idea de misterio y de religión a la luz de algunos estudios teológicos y filosóficos recientes.

Palabras clave: estética, hermenéutica, negatividad, mística

\begin{abstract}
Answers to Isabel Cabrera and Zenia Yébenes Escardó on the possibility of an Apophatic Aesthetics and its relation to the experience of the sacred in art. I return to te question of the opportunity of the idea of mistery and religion in relation to some new studies in theology and philosophy.
\end{abstract}

Key words: aesthetics, hermeneutic, negativity, mysticism

Las respuestas a mi texto, por parte de Zenia Yébenes Escardó e Isabel Cabrera, me dan ocasión para volver sobre algunos aspectos de mi exposición, con la intención de asumir el reto de las cuestiones planteadas, y, asimismo, introducir todavía algunas reflexiones de carácter siempre general, a propósito de lo que allí denominé: "estética apofática" y "hermenéutica del misterio".

Ciertamente, como indica Cabrera en su texto, "estética apofática" y "hermenéutica del misterio", ambas son expresiones que parecen referirse a lo mismo. Y en cierto modo así es, en la medida en que en una primera parte se exponen la historia y los motivos que darían ocasión a dicha expresión, mientras que en la segunda parte solamente se inicia una reflexión acerca del objeto de una hermenéutica del misterio en el contexto de una antropología espiritual. Son momentos diferentes de una misma reflexión: la estética, como resultado de mi aproximación a un caso concreto de obra de arte (Rothko), con la idea de partir de nuestra experiencia (estética) de la obra misma, de la observación de sus procesos morfológicos, etc., en lugar de proponer modos del comprender previos a toda experiencia sensible; y en el segundo caso,

${ }^{1}$ El carácter inevitablemente general de estas reflexiones, tanto en el artículo como en la contrarréplica a Yébenes y Cabrera, se debe a su función necesariamente propedéutica, a la espera de poder abordar un día cada uno de los elementos de nuestra crítica con mayor detalle y precisión. 
la hermenéutica, resultado de un ejercicio continuado de lectura de textos de la tradición espiritual (Llull y Eckhart, principalmente). Pero en mi exposición insisto en la necesidad de que una hermenéutica del misterio debería ser el preámbulo a toda hermenéutica, por el hecho de que la hermenéutica propuesta se alimenta de nuestra experiencia con las imágenes, y no ya con los textos; con unas imágenes que, sin embargo, deberían ser leídas como si de textos se trataran, es decir, con la conciencia histórica necesaria y con la clara intención de obtener un primer contexto de significación de los signos que la obra representa. La ausencia de una gramática de las imágenes del arte del siglo XX nos lleva a tener que interpretar los símbolos de esa escritura incomprensible a partir de la tensión entre figuración-desfiguración implícita en todo proceso artístico. En cierto modo, el momento apofático coincide con lo mistérico y es que son dos momentos del discurso de una misma acción expresiva; la primera, relativa a la expresión sensible de una imposibilidad, y la segunda, relativa a la comprensión e interpretación de esta misma imposibilidad; pero experiencia (sensible) y comprensión (inteligible) ocupan todavía para nosotros dos planos que, aunque alternativamente, se suceden respecto del objeto de su mostrarse. Y tal mostrarse impacta, como crisis, en el observador, produciendo emociones que sólo una hermenéutica de lo sensible/inteligible podría interpretar.

Pero el horizonte más amplio del significado de mi exposición viene determinado por la necesidad de una "crítica de la visibilidad". El abuso de las imágenes en nuestro tiempo, de su uso masivo en la transmisión de mensajes, así como la velocidad y densidad a la que someten nuestra percepción del mundo, da qué pensar acerca de las reacciones violentas que se han desencadenado en su contra en el transcurso de la historia. Probablemente, dicha presencia tan densa en nuestra exterioridad más cotidiana se deba a la pérdida de las estructuras analógicas que han permitido al hombre mantener una distancia prudente con el mundo de los dioses, un más allá protector, mientras se encuentra justamente en un afuera. A lo largo de la historia, la invasión alternativa de un plano sobre el otro ha tenido consecuencias desastrosas al quedar amenazado el campo intermedio en el que se desarrolla toda creatividad del espíritu. Con el derrumbe de las ontologías firmes y la aparición de otras fragmentadas, a lo largo de la segunda mitad de siglo veinte, ya no asistimos a una nueva confusión o inversión de planos, sino a un nuevo mapa, en el que el arriba y el abajo ya no son las únicas referencias de nuestra realidad. Todo parece moverse en un mar de fondo en el que el rumor incesante de las olas que llegan a la playa nos trae el 
recuerdo de una repetición, o de un retorno de lo igual, agotada ya toda facultad imaginativa que construya mundos diferentes en los intervalos $o$ intersticios que se crean continuamente.

Uno de los primeros aspectos sobre los que habría que volver, una y otra vez, es el de la muerte del dios metafísico, cuyas primeras formulaciones, como recuerda Zenia Yébenes, se remontan al himno luterano y acerca de cuya tradición, en la filosofía y la teología, Eberhard Jüngel ha escrito páginas memorables. ${ }^{2}$ También Mark C. Taylor, en su último libro, ${ }^{3}$ sitúa el origen de la secularización en Lutero y la influencia que sobre él tuvo el pensamiento de Ockham, así como de la tradición de la teología mística renana. Quizá lo más interesante del libro sea la insistencia de este autor en el hecho de que la secularización ha de entenderse como fenómeno religioso y no como su contrapartida. En cualquier caso, la teología de la muerte de Dios, cuya expresión más fuerte está en la escuela de Thomas Altizer, se sitúa en una perspectiva que quiere afirmar aquello que sólo puede ser dicho en modo negativo. Parece que nos encontramos en la escuela de Dionisio Areopagita: una teología del misterio, que en nuestro caso encontraría su recepción, que no su sustitución, en una hermenéutica del misterio, pues ni esta hermenéutica, ni una estética apofática como resultado de aquella, pretenden acallar los lenguajes religiosos. Tan sólo ponen en cuestión que el contexto de significados de lo religioso siga siendo privilegiado en la comunicación y expresión del misterio, pues si su capacidad de acogida en otros momentos de la historia ha sido ciertamente única, no parece que tras el derrumbe de la metafísica de corte dualista pueda continuarse del mismo modo. Ahora bien, ¿es posible una metafísica que no atienda ya a dos planos diferenciados de significación? No podemos entrar aquí en las derivaciones a que puede dar lugar una tal reflexión, simplemente destacaremos que el discurso sobre una naturaleza otra no tiene por qué obligarnos a situarnos de entrada en lo paradójico.

Creo que la dimensión del misterio a la que aspira una tal hermenéutica procede de un mundo anterior al inicio de la secularización con Lutero y que podría emerger de nuevo tras el debilitamiento de las hermenéuticas de origen exegético, cuyas últimas resoluciones se encuentran en los pensadores posmetafísicos. Pues si bien es cierto que, como ha visto, por ejemplo Hent de Vries, ${ }^{4}$ dicha filosofía adquiere su importancia en el giro religioso sufrido en los últimos años, habría que

${ }^{2}$ E. Jüngel, Dios como misterio del mundo, pp. $82 \mathrm{ss.}$

${ }^{3}$ M.C. Taylor, After God, pp. 43 ss.

${ }^{4}$ H. de Vries, Philosopy and the Turn to Religion.

Diánoia, vol. LIV, no. 62 (mayo 2009). 
preguntarse hasta qué punto sus horizontes de comprensión no quedan empalidecidos por la ausencia de fe en el misterio.

¿Cabe seguir haciendo una distinción entre lo apofático y lo catafático?, se pregunta Yébenes. La distinción tiene sólo un sentido ascético, purgativo, como en la secuencia de San Juan de la Cruz: "Para venir a gustarlo todo,/ no quieras tener gusto en nada", donde cada afirmación es un paso hacia adelante y cada negación un paso hacia atrás, mostrando en un mismo momento lo dinámico y lo estático de toda experiencia del misterio y, de este modo, la inutilidad de toda distinción que no sea comprendida, inevitablemente, en su secuencia temporal, aunque esta secuencia sea ritualmente repetitiva ("nada, nada, nada, nada, nada, y aun en el monte nada", dice Juan de la Cruz). La distinción revela la necesidad del plano hermenéutico como una propedéutica a todo acceso al misterio que se da continuamente. Es dicha continuidad el único plano en el que la comprensión se hace posible gracias a la distinción, a la separación a que nos obliga el misterio, es decir, al silencio de todo secreto. Sólo en esa perspectiva creo que toda negación debe preceder a cualquier afirmación como una réplica de aquel momento creador, cuyo primer paso es la autonegación, la contracción de la divinidad (tsim-tsum), lo cual en modo alguno hace de toda ausencia el núcleo de la negatividad; es decir, que no todo arte abstracto, como ha visto muy bien Yébenes, es un arte apofático, pues lo que hace apofático a la obra no es su apariencia y representación, sino su modo de ser producida, su emergencia: lo que Heidegger llama "surgir de la tierra", su manifestarse. Ahí, en ese modo de emergencia, no sujeto a nada dado previamente, radica su espíritu de desasimiento y libertad. Como ejemplo de esto, pienso que en muchos de los cuadros de "naturaleza muerta" de la pintura flamenca, entre los siglos XVI y XVII, hay algo muy próximo al espíritu del zen.

El problema de una estética apofática no es diferente de aquel de la teología negativa de raíz "dionisiana", en cuanto que lo negativo no es sino respuesta al límite de lo afirmativo, y viceversa, teniendo siempre presente que dicha limitación es un modo de descripción del modelo divino, en su "autolimitación", en el acto de la creación del mundo. ${ }^{5}$ Pero ¿es que esta estética puede ser otra cosa que negativa? Es estética porque ya se dispone como un discurso con pretensión metódica; pero no es ella la que da cuenta de la actividad creadora del artista, pues la estética no alcanza al arte en su emerger de la tierra, en su nacimien-

${ }^{5}$ G. Scholem, "Creación de la nada y autolimitación de Dios", en Conceptos básicos del judaísmo, pp. 47-74. 
to. La estética no da testimonio del aparecer. Ella sólo registra, en su discurso, el carácter ascético y negativo de las respuestas. Y no podría dejar de tener este carácter negativo dado que su modelo en la tradición de la teología negativa es la renuncia misma: renuncia en el acto creador (Génesis) y renuncia en la "Encarnación" (Jn) y renuncia en su comprensión histórica y doctrinal en la kenosis (Filipenses). El rostro catafático no es distinto del rostro apofático: éste es el silencio de aquél (su misterio por desvelar), pues todo misterio se da en lo revelado, dónde si no, ya que su modo del aparecer es en su estar velado, y su emergencia (apofatiké) es la apertura del silencio: su hablar es su callar. El problema mayor reside en comprender que sólo en el dinamismo propio del momento afirmativo queda anulada toda referencia anterior, ya dada, pues lo afirmativo no ocupa un lugar de prelación respecto de lo negativo.

¿Podemos hablar de experiencia sin mediación? Sólo si convenimos que en expresiones como la de Eckhart: "Dios es un modo sin modo" (wîse âne wîse), hay lugar para la experiencia. El problema, de nuevo, es el acceso a ese núcleo de realidad que se presenta imposible, pues como el mismo Eckhart dice: "no hay camino hacia Dios", o también Juan de la Cruz, en lo alto del ascenso al Montecillo de Perfección, escribe: "ya por aquí no hay camino". La experiencia requiere tiempo, camino, despliegue y continuidad, pero también es cierto que autores como éstos nos conducen al final de toda experiencia. Quizá la mística sea el final de toda experiencia religiosa.

\section{BIBLIOGRAFÍA}

Jüngel, E., Dios como misterio del mundo, trad. Fernando Carlos Vevia, Sígueme, Salamanca, 1984.

Scholem, G., Conceptos básicos del judaísmo, trad. J. L. Barbero, Trotta, Madrid, 1998.

Taylor, M.C., After God, The University of Chicago Press, Chicago, 2007.

Vries, H. de, Philosopy and the Turn to Religion, The Johns Hopkins University

Press, Baltimore/Londres, 1993.

Recibido el 19 de diciembre de 2008; aceptado el 5 de febrero de 2009. 